\title{
PLATAFORMAS DE COLHEITA E COLHEITA MANUAL COM TRILHA MECÂNICA SOBRE A QUALIDADE DE SEMENTES DE ARROZ (Oryza sativa, L. )
}

\author{
HARVEST HEADER AND MANUAL HARVEST WITH MECHANICAL \\ STRIP ON RICE ( Oryza sativa, L. ) SEEDS QUALITY
}

\section{Daniel Fernandez Franco $^{1}$ Airton dos Santos Alonço ${ }^{2}$ José Alberto Petrini $^{1}$}

RESUMO

Durante a colheita do arroz irrigado ocorrem perdas e danos físicos e fisiológicos às sementes. No final da década de oitenta, surgiram as plataformas recolhedoras, que retiram ou arrancam o grão ao invés de cortar a panícula, porém, pouco se conhece a respeito dos danos físicos e fisiológicos que este sistema de plataforma pode causar às sementes. Este trabalho teve por objetivo avaliar os danos mecânicos causados às sementes dos cultivares de arroz BR-IRGA 409 e BR-IRGA 410, por três formas de colheita: (a) colheita manual e trilha mecânica; (b) colheita com plataforma de corte; (c) colheita com plataforma recolhedora. Quando a colheita foi mecânica, realizou-se a coleta das amostras diretamente no graneleiro. $O$ delineamento experimental foi blocos ao acaso, com seis repeticões. Os resultados demonstraram que as sementes de arroz irrigado dos cultivares estudados não apresentaram diferenças significativas em suas qualidades físicas e fisiológicas, quando colhidas com plataforma de corte e com a plataforma recolhedora. Estes dois métodos de colheita, porém, apresentaram danos significativamente maiores quando comparados à colheita manual e trilha mecânica.

Palavras-chave: colheita mecânica, plataforma de corte, plataforma recolhedora.

\section{SUMMARY}

During irrigated rice harvesting occur losses and physical and phisiological seed damage. Late 80's, appeared the strippers headers that strip the grain, instead of cutting the spike. However, little is know about physical and phisiological seed damage by harvest header. The objective of this work was to evaluate the mechanical damage caused to BR-IRGA 409 and BR-IRGA 410 rice cultivars by three harvesting methods: (a) manual harvesting and mechanical strip; (b) cutterbar harvesting and; (c) stripper header harvesting. Samples were collected directly in the grain tank when the harvest was mechanical. The experimental design was randomized blocks with six replications. Results demonstrated that the rice seeds of the studied variety didn't showed significant differences in physical and phisiological in seed quality when harvested by cutterbar or stripper header. These two harvesting forms, however, showed significantly seed damages when compared to manual harvesting and mechanical strip.

Key words: harvest, vutterbar header, stripper header.

\section{INTRODUÇÃO}

O ponto de colheita do arroz é determinado, basicamente, pelo teor de umidade das sementes. O ideal seria colhê-las e limpá-las à mão para evitar danos; entretanto, isso não é prático e nem econômico. É difícil realizar a colheita sem que perdas e danos físicos e fisiológicos ocorram às sementes. A má regulagem e o princípio de construção das colhedoras convencionais impedem o recolhimento adequado de todas as sementes. Mesmo com colhedoras modernas, quando perfeitamente reguladas, as panículas e as sementes sofrem batidas ou choques durante a operação de debulha, causando quebras e injúrias, principalmente se as sementes forem colhidas com teor de umidade inadequado. HARMOND (1967) afirmou que a colheita em época inadequada e os ajustes da colhedora são as causas de maiores perdas durante a colheita. A época inadequada, o ajuste da velocidade do cilindro, a abertura do côn-

\footnotetext{
${ }^{1}$ Engenheiro Agrônomo, Mestre, EMBRAPA/CPACT, Pelotas/RS.

${ }^{2}$ Engenheiro Agrícola, Mestre, Professor Assistente, Departamento de Engenharia Rural, Centro de Ciências Rurais, Universidade Federal de Santa Maria, RS, 97105-900. E. Mail: alonco@ ccr.ufsm.br. Autor para correspondência.
} 
cavo e das peneiras da colhedora, e ainda a velocidade de operação em que a cultura é colhida desempenham um importante papel na redução das perdas, tanto qualitativas quanto quantitativas. $\mathrm{O}$ autor afirmou ainda, que sementes com teor de umidade muito alto são difíceis de debulhar, sendo descartadas pelo saca-palhas da máquina. Quando o teor de umidade é baixo, o cilindro quebra as sementes e mastiga a palha.

Para MACIEL (1977), a colheita mecanizada é fonte de danos às sementes uma vez que os mecanismos de debulha são construídos de modo a funcionar rápida e eficientemente na colheita de grãos, não levando em conta sua utilização na colheita de sementes, cuja qualidade é importante. Mesmo assim, danos mecânicos ocorrem quando da colheita de grãos influenciando diretamente no rendimento de engenho.

Segundo Whitney, citado por LISBÃO (1974), a trilha é responsável por grande parte dos danos à semente, razão por que maior atenção deveria ser dada à velocidade de deslocamento da colhedora e às condições de temperatura e umidade na ocasião da colheita. POLLOCK \& ROOS (1972) afirmaram que quanto mais rápida é a rotação do cilindro de trilha da colhedora, tanto melhor será a debulha, mas também maior será o dano mecânico e, afirmaram ainda, que quanto mais alto for o teor de umidade das sementes maior será o dano mecânico.

As colhedoras modernas representavam o que existia de mais avançado em tecnologia de colheita. As utilidades destas máquinas têm sido amplamente demonstradas e, tecnicamente, para LEES (1992), muito pouco poderá ser feito para extrairlhes mais eficiência ou benefícios adicionais. No fim da década de 80 , surgiram as chamadas plataformas recolhedoras ("strippers"). Estes equipamentos retiram ou arrancam o grão ao invés de cortar a panícula, como fazem as colhedoras equipadas com plataformas convencionais. ALONÇO \& REIS (1997) salientam que a colhedora operando com plataforma recolhedora executa a colheita do arroz a uma velocidade $25 \%$ maior, comparada à colheita convencional.

O sistema de colheita com plataforma recolhedora, acoplada à colhedora, foi introduzido no Brasil, por volta de 1990, com o objetivo de colher grão em função de sua alta eficiência; entretanto, vem sendo utilizado, também, na colheita de sementes. Pouco se conhece a respeito dos danos físicos e fisiológicos que esse sistema de colheita pode causar às sementes. Em função do exposto, este trabalho teve por objetivo avaliar os efeitos da colheita de arroz irrigado, através do sistema de colheita convencional (plataforma de corte) e com plataforma recolhedora (stripper) de sementes aco- plada à colhedora, sobre a qualidade física e fisiológica das sementes, tendo como testemunha, a fim de evitar danos mecânicos às sementes, a colheita manual.

\section{MATERIAL E MÉTODOS}

O trabalho foi realizado na Granja "Quatro Irmãos", no município de Rio Grande/RS e, no Laboratório de Análise de Sementes da EMBRAPACPACT, nos anos agrícolas de 1994/95 e 1995/96.

Sementes de arroz irrigado, dos cultivares BR-IRGA 409 (experimento 1) e BR-IRGA 410 (experimento 2), foram submetidas a três sistemas de colheita: (a) colheita manual (testemunha); (b) colheita com plataforma de corte (convencional) e, (c) colheita com plataforma recolhedora (stripper) acoplada à colhedora automotriz. O delineamento experimental utilizado, nos dois experimentos, foi o de blocos ao acaso, com parcelas de $25,00 \times 4,10 \mathrm{~m} \mathrm{e}$ seis repetições para cada cultivar estudado. Utilizouse, para realizar a colheita mecânica, uma colhedora Massey-Ferguson, modelo 3640, Motor Perkins ${ }^{\mathrm{a}}$. A6.358 com potência de $105 \mathrm{CV}$ a $2200 \mathrm{rpm}$, dotada de pneus. As plataformas utilizadas foram: (a) plataforma de corte rígida Massey-Ferguson ${ }^{3}$, com largura de $4,10 \mathrm{~m}$, dotada de molinete recolhedor, sendo que o mesmo, atendendo às recomendações contidas no Manual do Operador da Máquina, foi alterado em função da velocidade de deslocamento e (b) plataforma recolhedora Turbomax ${ }^{3}$, modelo JLT 2001, com largura de 4,10m, com rotor de 8 lâminas de pentes recolhedores de poliuretano pu $\mathrm{ARLON}^{\mathrm{a}}$, marca Ipubrás ${ }^{\text {, com }} 118 \mathrm{~mm}$ de comprimento, espessura de $10 \mathrm{~mm}, 20 \mathrm{~mm}$ de diâmetro do círculo interno e ângulo de ponta de $26^{\circ}$.

As regulagens feitas na máquina para realização do trabalho foram as seguintes: (a) rotação do cilindro de trilha: 800rpm; (b) abertura do côncavo (frente): 14,0mm; (c) abertura do côncavo (atrás): 5,0mm; (d) abertura da peneira superior: 17,5mm; (e) abertura da peneira inferior: $8,0 \mathrm{~mm}$; (f) rotação do ventilador: $1850 \mathrm{rpm}$ e (g) rotação do cilindro recolhedor: $860 \mathrm{rpm}$.

A média das velocidades de deslocamento da colhedora com plataforma convencional foi de $2,08 \mathrm{~km} / \mathrm{h}$ e, com a plataforma recolhedora ("stripper") de $4,5 \mathrm{~km} / \mathrm{h}$. Estas velocidades estão muito próximas de onde ocorrem os menores percentuais de perdas totais na colheita de arroz irrigado.

O trabalho foi realizado em condições semelhantes de temperatura e umidade relativa do ar, $30^{\circ} \mathrm{C}$ e $70 \%$, respectivamente. As lavouras, onde foram desenvolvidos os testes, apresentavam as características expressas na tabela 1. 
Tabela 1 - Características das lavouras onde foram desenvolvidos os testes. EMBRAPA / CPACT. Pelotas, 1997.

CARACTERÍSTICAS DAS LAVOURAS ESTUDADAS
CULTIVAR DE ARROZ IRRIGADO BR -IRGA $409 \quad$ BR-IRGA 410
Altura média das plantas ( $\mathrm{m}$ )

Número de perfílios por metro linear

Espaçamento entre linhas ( $\mathrm{m}$ )

Produtividade média ( $\mathrm{kg} / \mathrm{ha}$ )

Umidade média dos grãos colhidos ( \%)

Umidade média da palha ( \%)

Peso de 100 grãos ( g )

$\begin{array}{cc}0,79 & 0,81 \\ 93,4 & 96,7 \\ 0,20 & 0,20 \\ 5267 & 5732 \\ 18,70 & 19,80 \\ 90,20 & 96,50 \\ 2,46 & 2,76\end{array}$

nação da percentagem de grãos fissurados, as amostras (quatro repetições de 100 sementes) foram avaliadas sob luz com lâmpada de 40 watts.

$\mathrm{Na}$ avaliação da qualidade fisiológica das sementes, foram utilizadas a percentagem de germinação (BRASIL, 1992) e a percentagem de vigor, obtidas pelo teste de envelhecimento precoce (DELOUCHE \& BASKIN, 1973) e frio modificado (CÍCERO \& VIEIRA, 1994). Os resultados foram comparados estatisticamente pelo teste de Duncan em nível de $5 \%$ de probabilidade.
Na colheita mecânica, realizou-se a coleta das amostras de sementes diretamente do graneleiro. $\mathrm{Na}$ colheita manual, as sementes foram colhidas e trilhadas em trilhadora estacionária, marca Bill's Welding $^{\mathrm{a}}$, tendo seu cilindro de trilha apresentado uma rotação média de $774 \mathrm{rpm}$. Após a coleta das amostras de sementes, foi retirada uma subamostra para determinação da umidade. O restante das sementes foram secas em estufa, com circulação de ar e temperatura de $35^{\circ} \mathrm{C}$, até $13 \%$ de umidade. Após a secagem, retiraram-se amostras para avaliação da qualidade física e fisiológica. O restante foi armazenado em câmara, a $20^{\circ} \mathrm{C}$ de temperatura e $50 \%$ de umidade relativa, por um período de 7 meses, para avaliação da qualidade fisiológica.

Para avaliação da qualidade física, retiraram-se, de cada amostra, 100g de sementes para determinação da porcentagem de pureza, impurezas, grãos quebrados e grãos descascados. Para determi-

\section{RESULTADOS E DISCUSSÃO}

Na tabela 2, são apresentados os resultados obtidos para o efeito de três métodos de colheita, sobre a qualidade física, em sementes de arroz irrigado para os cultivares BR-IRGA 409 e BR-IRGA 410. Com relação aos parâmetros físicos, a análise dos dados indicou um comportamento semelhante para os dois cultivares. Para a variável percentagem de impurezas, não houve diferenças significativas nos três métodos de colheita, para os dois cultivares. Para s variáveis percentagem de grãos quebrados, percentagem de grãos descascados e percentagem de grãos fissurados, verificou-se que o sistema de colheita convencional e o de colheita com plataforma recolhedora ("stripper") não apresentaram diferenças significativas (em ambos os cultivares), entretanto, diferiram significativamente quando comparadas com o sistema de colheita manual. Esses resultados
Tabela 2 - Percentagem média de sementes puras, impurezas, grãos quebrados, grãos descascados e grãos fissurados obtidos através de três métodos de colheita, em sementes de arroz irrigado dos cultivares BR-IRGA 409 e BR-IRGA 410. EMBRAPA/CPACT. Pelotas, 1997.

\begin{tabular}{|c|c|c|c|c|c|}
\hline $\begin{array}{c}\text { MÉTODOS DE } \\
\text { COLHEITA } \\
\text { (TRATAMENTOS) }\end{array}$ & $\begin{array}{c}\text { SEMENTES } \\
\text { PURAS } \\
(\%)\end{array}$ & $\begin{array}{l}\text { IMPUREZAS } \\
(\%)\end{array}$ & $\begin{array}{c}\text { GRÃOS } \\
\text { QUEBRADOS } \\
(\%)\end{array}$ & $\begin{array}{c}\text { GRÃOS } \\
\text { DESCASCADOS } \\
(\%)\end{array}$ & $\begin{array}{c}\text { GRÃOS } \\
\text { FISSURADOS } \\
(\%)\end{array}$ \\
\hline \multicolumn{6}{|c|}{ BR-IRGA 409} \\
\hline Manual & $98,2 \mathrm{a}$ & $1,74 \mathrm{a}$ & $0,00 \mathrm{a}$ & $0,00 \mathrm{a}$ & $0,00 \mathrm{a}$ \\
\hline Convencional & $97,8 \mathrm{a}$ & $1,51 \mathrm{a}$ & $0,46 \mathrm{~b}$ & $0,45 \mathrm{~b}$ & $2,42 b$ \\
\hline Recolhedora & $97,5 \mathrm{a}$ & $0,91 \mathrm{a}$ & $0,57 \mathrm{~b}$ & $0,62 \mathrm{~b}$ & $4,62 \mathrm{~b}$ \\
\hline \multicolumn{6}{|c|}{ BR-IRGA 410} \\
\hline Manual & $97,4 \mathrm{a}$ & $2,60 \mathrm{a}$ & $0,00 \mathrm{a}$ & $0,00 \mathrm{a}$ & $0,00 \mathrm{a}$ \\
\hline Convencional & $96,8 \mathrm{a}$ & $2,18 \mathrm{a}$ & $0,60 \mathrm{~b}$ & $0,57 \mathrm{~b}$ & $3,00 \mathrm{~b}$ \\
\hline Recolhedora & $96,3 \mathrm{a}$ & $2,26 a$ & $0,80 \mathrm{~b}$ & $0,62 \mathrm{~b}$ & $4,20 \mathrm{~b}$ \\
\hline
\end{tabular}

Médias seguidas pela mesma letra não diferem entre si, em nível de 5\% de probabilidade, pelo teste de Duncan. 
estão de acordo com ALONÇO \& REIS (1997), visto que sementes colhidas manualmente, mesmo que trilhadas mecanicamente, são menos sujeitas a danos provenientes da colhedora, em função do menor número de mecanismos pelos quais passam as sementes. As sementes colhidas mecanicamente sofrem golpes e impactos diversos, provenientes do molinete, da plataforma de corte e do sistema de trilha e limpeza da máquina, o que provoca danos físicos às sementes, resultando em aumento nas percentagens de grãos quebrados, descascados e fissurados.

MACIEL (1977) salienta que em arroz irrigado os danos mecânicos terão uma influência direta na quantidade de grãos inteiros.

$\mathrm{Na}$ tabela 3, são apresentados os resultados para o efeito de três métodos de colheita, sobre a qualidade fisiológica de sementes de arroz irrigado, dos cultivares BR-IRGA 409 e BR-IRGA 410, após a colheita e após um período de armazenamento de sete meses, sob condições de $20^{\circ} \mathrm{C}$ de temperatura e $50 \%$ de umidade relativa do ar.

Com relação à percentagem de germinação, verificou-se após o período de armazenamento que o sistema de colheita convencional e de colheita com plataforma recolhedora ("stripper") não apresentaram diferenças significativas. Entretanto, diferiram do sistema de colheita manual. Este comportamento da germinação das sementes de arroz era esperado, visto que durante a colheita mecanizada as sementes estão sujeitas a impactos e abrasões. As lesões que as sementes sofrem durante a colheita, em geral, vão refletir-se após o período de armazenamento, mesmo sob condições controladas, como observa-se na tabela 3 .

Os efeitos dos danos mecânicos se tornaram mais evidentes ao observarem-se os resultados de percentagem de vigor das sementes, obtidos pelos testes de envelhecimento precoce e do de frio modificado (tabela 3). Verifica-se para o cultivar BRIRGA 409, que as sementes, colhidas manualmente, apresentaram qualidade superior quando comparadas com as sementes colhidas mecanicamente após a colheita e após o período de armazenamento. Para o cultivar BR-IRGA 410 não foram encontradas diferenças significativas entre os sistemas de colheita, quando avaliados pelo teste de vigor, logo após a colheita. Entretanto, foram encontradas diferenças significativas quando comparados os sistemas de colheita, através do teste de vigor após o armazenamento sob condições controladas. Isso pode ser atribuído ao teste de vigor não ter conseguido detectar, após a colheita, as pequenas modificações ocorridas nas sementes e sim após um determinado período de armazenamento. POPINI-GIS (1977) salienta que muitas vezes o efeito dos danos mecânicos reflete-se após um determinado período de armazenamento, e pode ser detectado não somente pelos testes de vigor, mas também pelo teste de germinação.

\section{CONCLUSÃO}

As sementes de arroz irrigado dos cultivares BR- IRGA 409 e BR- IRGA 410 não apresentam diferenças significativas nas qualidades físicas e fisiológicas estudadas, quando colhidas através do sistema de colheita convencional ou através do sistema com plataforma recolhedora.

\section{COMUNICAÇÃO PESSOAL}

a - A citação de marcas e modelos comerciais não implica nenhuma forma de aprovação ou recomendação dos mesmos por parte dos autores ou das instituições. 


\section{REFERÊNCIAS BIBLIOGRÁFICAS}

ALONÇO, A. dos S., REIS, Â.V. dos Perdas na colheita mecânica de grãos. Pelotas: EMBRAPA/CPACT, 1997. 27 p. ( EMBRAPA-CPACT. Documentos, 35 ).

BRASIL. Ministério da Agricultura e Reforma Agrária Departamento Nacional de defesa Vegetal. Coordenação de Laboratório Vegetal. Regras para análise de sementes. Brasília, 1992.

CÍCERO, S.M., VIEIRA, R.D. Teste de frio. In: VIEIRA, R.D.; CARVALHO, N.M. Testes de vigor em sementes. Jaboticabal: FUNEP, 1994, p. 151-164.

DELOUCHE, J.C., BASKIN, C.C. Accelerated aging techinics for predicting the relative storability of seed lots. Seed Sci \& Technology, v. 1, n. 2, p. 427-52. 1973.

HARMOND, J.E. Seed harvesting losses, causes and cures.
Paper reprinted from Crop \& Soils Magazine. Wisconsin, 1967. (mimeografado).

LEES, P. Cabezales despojadores. Agricultura de las Americas, New York, v. 41, n. 2. p. 20-24, 1992.

LISBÃO, R.S. Danificações mecânicas em sementes de feijoeiro. Piracicaba: Centro Acadêmico "Luiz de Queiróz", Universidade de São Paulo, 1974. p. 73-100 (mimeografado)

MACIEL, V.S. Perdas e danificações mecânicas de sementes de arroz ( Oryza sativa, L. ) durante a colheita. Pelotas, 1977. 80 p. Dissertação (Mestrado) - Pelotas, Universidade Federal de Pelotas, 1977.

POLLOCK, B.M., ROOS, E.E. Mechanical demage and vigor reduction. In: KOSLOWSKI, T.T. (Ed). Seed Biology Madison: Academic Press, 1972, v. 1., p. 352-59.

POPINIGIS, F. Fisiologia da semente. Brasília: AGIPLAN, 1977. Fatores que afetam a qualidade fisiológica das sementes: p. 203-233.

Ciência Rural, v. 29, n. 2, 1999. 